\title{
Causes and consequences of gestational diabetes in South Asians living in Canada: results from a prospective cohort study
}

\author{
Sonia S. Anand MD, Milan Gupta MD, Koon K. Teo MBBCh, Karleen M. Schulze MMath, \\ Dipika Desai MSc, Nora Abdalla MBBCh, Michael Zulyniak PhD, Russell de Souza BA, Gita Wahi MD, \\ Mateen Shaikh PhD, Joseph Beyene PhD, Eileen de Villa MD, Katherine Morrison MD, \\ Sarah D. McDonald MD, Hertzel Gerstein MD; for the South Asian Birth Cohort (START) - Canada \\ Investigators
}

\section{Abstract}

Background: The reasons for the increased risk of gestational diabetes among South Asian women are not well understood. We sought to identify the determinants of gestational diabetes and its impact on newborn health in a prospective birth cohort of South Asian women and their babies.

Methods: As part of the South Asian Birth Cohort (START) prospective birth cohort study in Ontario, we recruited 1012 South Asian women with singleton pregnancies in the second trimester of pregnancy between July 11, 2011, and Nov. 10, 2015. We collected health information and physical measurements and administered an oral glucose tolerance test. Birth weight and skinfold thickness measurements were obtained from their newborns, and cord blood glucose and insulin levels were measured.

Results: The incidence of gestational diabetes was 36.3\% (95\% confidence interval $[\mathrm{Cl}] 33.3 \%-39.3 \%)$; the age-standardized rate was $40.7 \%$. Factors associated with gestational diabetes included maternal age (odds ratio [OR] 1.08 [95\% Cl 1.04-1.12]), family history of diabetes (OR 1.65 [95\% Cl 1.26-2.17]), prepregnancy weight (OR 1.025 [95\% Cl 1.01-1.04]) and low diet quality (OR 1.57 $[95 \% \mathrm{Cl} 1.16-2.12])$. Maternal height was protective against gestational diabetes (OR 0.97 [95\% Cl 0.95-0.99]). The population attributable risk due to prepregnancy body mass index and low diet quality was $37.3 \%$. Compared to newborns of women without gestational diabetes, those of women with gestational diabetes had a significantly higher birth weight (3267 [standard error (SE) 23] g v. 3181 [SE 17] g, $p=0.005$ ), greater skinfold thickness (11.7 [SE 0.1] mm v. 11.2 [SE 0.1] mm, $p=0.007$ ) and lower insulin sensitivity (glucose/insulin ratio 0.092 [SE 0.009$] \mathrm{mmol} / \mathrm{pmol}$ v. 0.129 [SE 0.006] $\mathrm{mmol} / \mathrm{pmol}, p=0.001$ ).

Interpretation: The modifiable risk factors of prepregnancy weight and low diet quality accounted for $37 \%$ of the population attributable risk of gestational diabetes in our cohort. Intervention studies to lower prepregnancy weight and to prevent gestational diabetes among South Asian women in high-income countries are needed.

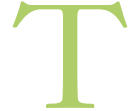
he prevalence of gestational diabetes mellitus is growing worldwide. Gestational diabetes increases the risk of large-for-gestational-age newborns, delivery complications and future type 2 diabetes among both the woman and her baby. ${ }^{1-4}$

South Asian migrants to high-income countries including the United Kingdom, United States and Canada have an excess prevalence of abdominal obesity and type 2 diabetes ${ }^{5-10}$ and a twofold increased risk of gestational diabetes compared to white people. ${ }^{11-14}$ The reasons for the increased risk of gestational diabetes among South Asians are not well understood. Prior analyses of multiethnic cohorts identified advanced maternal age, family history of diabetes, nonwhite ethnicity, maternal overweight or obesity, and cigarette smoking as common predictors of gestational diabetes. ${ }^{15-17}$ Among women living in India, increased age, small stature, urban living, a family history of diabetes, parity of 3 or more children and low vitamin $B_{12}$ levels are associated with the increased prevalence of gestational diabetes. ${ }^{18-20}$ Specific prevention strategies for this high-risk ethnic group are lacking. ${ }^{21-24}$

\section{Competing interests: None declared.}

This article has been peer reviewed.

Correspondence to: Sonia Anand, anands@mcmaster.ca

CMAJ Open 2017. DOI:10.9778/cmajo.20170027 
In this prospective birth cohort study conducted among South Asian women living in Ontario, we sought to determine 1) the maternal factors associated with gestational diabetes and 2) the impact of gestational diabetes on newborn anthropometric characteristics including birth weight, body fat and insulin sensitivity.

\section{Methods}

\section{Design and setting}

The South Asian Birth Cohort (START) study is a prospective birth cohort study among South Asian women with singleton pregnancies in Ontario. ${ }^{25}$ The goal was to recruit about 1000 participants between July 11, 2011, and Nov. 10, 2015. Participants were recruited during the second trimester of pregnancy from Brampton and Mississauga, Ontario by referral from family practitioners and obstetricians who were familiar with the study.

\section{Maternal measurements}

Participants who did not have preexisting diabetes underwent a 75 -g oral glucose tolerance test. We classified gestational diabetes using the cut-off values derived from the Born in Bradford cohort of South Asian women: a fasting glucose level of $5.2 \mathrm{mmol} / \mathrm{L}$ or higher, or a 2 -hour postload level of $7.2 \mathrm{mmol} / \mathrm{L}$ or higher. ${ }^{26}$ These cut-off values were recently shown to be associated with high infant birth weight (> 90th percentile for gestational age) and adiposity (sum of skinfold measurements $>$ 90th percentile for gestational age) in 5408 babies born to South Asian women in the UK. ${ }^{26}$ All participants completed health questionnaires including self-reported personal and family medical history, social and cultural questions, physical activity and sedentary behaviours during work and leisure time, ${ }^{27}$ and a previously validated ethnicity-specific food frequency questionnaire. ${ }^{28}$ We scored diet quality as follows: 1 point was given for consuming more than the study population median of 1) green vegetables, 2) raw vegetables, 3) cooked vegetables and 4) fruits, or less than the study population median of 5) fried foods and 6) meat (Table 1). ${ }^{25}$ The

\begin{tabular}{ll}
$\begin{array}{l}\text { Table 1: Foods in low- versus high-quality diet among South } \\
\text { Asians in pregnancy }\end{array}$ \\
$\begin{array}{ll}\text { Foods consumed in greater } \\
\text { quantity in low-quality diet }\end{array}$ & $\begin{array}{l}\text { Foods consumed in greater } \\
\text { quantity in high-quality diet }\end{array}$ \\
\hline $\begin{array}{l}\text { Meat, meat dishes, processed } \\
\text { meats, organ meats, poultry }\end{array}$ & Vegetables, raw and cooked \\
\hline Fish, seafood & Legumes (daals) \\
\hline Rice & Nuts and seeds \\
\hline Fried foods & $\begin{array}{l}\text { Low-fat dairy products (low-fat } \\
\text { and fermented) }\end{array}$ \\
\hline $\begin{array}{l}\text { Refined grains (breads and } \\
\text { cereals) }\end{array}$ & $\begin{array}{l}\text { Whole grains (breads and } \\
\text { cereals) }\end{array}$ \\
\hline Fast foods & Sweets \\
\hline Eggs & Fruits \\
\hline
\end{tabular}

score ranged from 0 to 6 ; diet quality was classified as low (0 or 1 ), intermediate (2 or 3) or high (4-6). ${ }^{29}$ We determined social disadvantage using a previously validated index that includes employment, marital status and income. ${ }^{30} \mathrm{We}$ used a standardized protocol to measure resting blood pressure with an oscillometric device (OMRON Healthcare), body weight, height, hip circumference and skinfold thickness. We estimated body fat by summing the skinfold thickness values from triceps and subscapular sites. ${ }^{31}$ We calculated weight gain during pregnancy by subtracting the prepregnancy weight (self-reported) from the weight immediately before delivery. Participants were considered to have a family history of diabetes if either their mother or father had a history of type 2 diabetes.

\section{Delivery characteristics and newborn measurements}

Type, duration and outcomes of labour as well as birth weight were obtained from hospital charts by trained research assistants. Placental weight was determined by reducing the untrimmed complete placenta weight, as measured at delivery, to a trimmed weight. ${ }^{32}$ Infants born at 37 weeks' gestation or later were classified as large for gestational age or small for gestational age by gestational age and sex-specific cut-points of 90th percentile or more, and less than 10th percentile, respectively. ${ }^{33}$ Trained research assistants measured the newborns' length using an O'Leary length board, head circumference using a nonstretchable measuring tape, and waist and hip circumference using an Ohaus nonstretchable tape with an attached spring balance. The skinfold thickness of triceps and subscapular sites was measured 3 times and was recorded to the nearest millimetre using Holtain calipers (dial graduation $0.2 \mathrm{~mm}$ ). The intraclass correlation (reliability) for skinfold measurements was 0.98 for subscapular sites and 0.96 for triceps sites. ${ }^{34}$ The ponderal index was calculated as birth weight/length ${ }^{3}{ }^{33}$ These measures were obtained within 24 hours after delivery in $81.0 \%$ of newborns and within 25-96 hours after delivery in $7.6 \%$. If no measurements were obtained within 96 hours, the chart recording of measurement was used, if available.

A cord blood sample was collected from the umbilical vein. Within 2 hours, the sample was centrifuged and sample aliquots were frozen at $-70^{\circ} \mathrm{C}$ and shipped for storage in liquid nitrogen at the Clinical Research Laboratory and Biobank, Hamilton Health Sciences. All suitable samples in which 1 serum aliquot was available were analyzed for glucose and insulin. Glucose level was measured with the UniCel DxC 600 Synchron clinical system (Beckman Coulter) with a timed end-point method. Insulin level was measured with the Elecsys 2010 immunoassay analyzer (Roche Diagnostics) by means of an electrochemiluminescence immunoassay. The coefficients of variation for glucose level and insulin level were $24.4 \%$ and $84.6 \%$, respectively.

\section{Statistical analysis}

We performed statistical analyses using SAS version 9.4 (SAS Institute). We calculated means (and standard deviations $[\mathrm{SDs}]$ ) and counts to summarize continuous variables 
and categorical data, respectively, and means (and standard errors [SEs]) for adjusted continuous results. The incidence of gestational diabetes was directly age-standardized to the general Canadian population with the 2011 census population for women aged 20-44 years as the standard population. ${ }^{35} \mathrm{We}$ assessed the univariate associations between maternal factors and gestational diabetes using the $\chi^{2}$ test for categorical variables and the Student $t$ test for continuous variables, as appropriate. Factors with a univariate $p$ value of $>0.10$ were then considered for a multivariable logistic regression model; for any set of factors that were highly correlated, only 1 factor was included. We used stepwise selection methods to determine the final model. We assessed the univariate associations between newborn anthropometric characteristics and maternal gestational diabetes using analysis of covariance, adjusting for gestational age, infant's sex and maternal insulin use during pregnancy. We estimated population attributable risk using the Interactive Risk Attributable Program (US National Cancer Institute). ${ }^{36}$ Population attributable risk is calculated by considering the frequency of the exposure in the population and the relation of the risk factor to disease. In the current study, population attributable risk quantifies the proportion of cases of gestational diabetes that can be prevented if a specific exposure is eliminated from the study population while other exposures are held constant.

\section{Ethics approval}

The study was approved by the Hamilton Integrated Research Ethics Board, William Osler Health System and Trillium Health Partners.

\section{Results}

Of the 1012 participants with singleton pregnancies enrolled, 4 with a history of diabetes and 2 who withdrew early were excluded from this analysis. Among the remaining 1006 participants, gestational diabetes status was classified according to the result of the oral glucose tolerance test (performed on average at 26.5 [SD 1.6] weeks' gestation) in 945 and as reported on the birth chart in 61 . Of the 1006 women, 365 (36.3\% [95\% confidence interval (CI) 33.3\%-39.3\%]) were classified as having gestational diabetes; the age-standardized rate was $40.7 \%$.

Among the 1006 cases, sex, gestational age and birth weight were available for 989 newborns $(98.3 \%)$.

\section{Characteristics of participants with and without gestational diabetes}

Compared to the participants without gestational diabetes, those with gestational diabetes were older (mean age 31.2 [SD 4.0]) yr v. 29.7 [SD 3.8]) yr, $p<0.001$ ) and were more likely to have a family history of diabetes (191 [52.5\%] v. 228 [35.7\%], $p<0.001)$, be multiparous (236 [65.7\%] v. 343 $[54.8 \%], p<0.001)$, have a higher prepregnancy weight (mean 64.9 [SD 12.2] kg v. 61.3 [SD 11.8] kg, $p<0.001$ ), be shorter (mean height 161.6 [SD 6.2] cm v. 162.5 [SD
6.3] $\mathrm{cm}, p=0.02)$, have a higher prepregnancy body mass index (BMI) (mean 24.9 [SD 4.6] v. 23.2 [SD 4.3], $p<0.001$ ), have more body fat (mean sum of skinfold measurements 52.3 [SD 12.3] $\mathrm{mm}$ v. 47.9 [SD 12.4] $\mathrm{mm}, p<0.001)$ and consume a low-quality diet (121 [33.4\%] v. 145 [22.9\%], $p<$ 0.001 ) (Table 2). There were no differences between the 2 groups in vegetarianism, physical activity in pregnancy or socioeconomic status.

Women with gestational diabetes were more likely than those without gestational diabetes to have had a cesarean delivery (127 [35.2\%] v. 177 [27.9\%], $p=0.02)$.

\section{Multivariable predictors of gestational diabetes}

Factors independently associated with an increased risk of gestational diabetes included maternal age (per 1-yr increase odds ratio [OR] 1.08 [95\% CI 1.04-1.12]), family history of diabetes (OR 1.65 [95\% CI 1.26-2.17]), prepregnancy weight (per 1-kg increase OR 1.025 [95\% CI 1.01-1.04]) and low diet quality (OR 1.57 [95\% CI 1.16-2.12]) (data not shown). The only protective factor was maternal height (per $1-\mathrm{cm}$ increase OR 0.97 [95\% CI 0.95-0.99]). Using the prevalence rates and ORs of these independent factors, we estimated that they accounted for $65.3 \%$ (95\% CI $55.6 \%-75.1 \%$ ) of the population attributable risk for gestational diabetes (Figure 1, Table 3). The modifiable risk factors of low diet quality and prepregnancy BMI greater than 23 accounted for $37.3 \%$ of the population attributable risk $(95 \%$ CI 25.9-48.7).

\section{Newborn measurements}

Of the 989 infants, 58 (5.9\%) were delivered before 37 weeks, and $2(0.2 \%)$ were stillborn. Triceps and subscapular skinfold measurements were available for 937 newborns (94.7\%); however, in the current analysis, we included only 839 newborns $(84.8 \%)$ whose measurements were taken within 4 days of birth.

After adjustment for gestational age, newborn sex and maternal use of insulin during the pregnancy, infants of women with gestational diabetes had a higher birth weight 3267 (SE 23) g v. 3181 (SE 17) g, $p=0.005$ ), ponderal index (24.8 [SE 0.2] v. 24.0 [SE 0.1], $p=0.002)$ and skinfold thickness (11.7 [SE 0.1] $\mathrm{mm}$ v. 11.2 [SE 0.1] $\mathrm{mm}, p=0.007)$ than those of women without gestational diabetes (Table 4). A higher proportion of newborns of women with gestational diabetes than those of women without gestational diabetes were large for gestational age (48 [13.8\%] v. 55 [9.0\%], $p=$ 0.02 ), and placental weight was higher in the former group (503.2 [SE 8.1] g v. 474.9 [SE 5.8] g, $p=0.007$ ).

A cord blood sample was collected in 777 cases (77.2\%). Glucose and insulin were analyzed in 638/777 samples (82.1\%). No difference in glucose level was observed between the 2 groups. The insulin $(\log )$ level was higher in the infants of women with gestational diabetes $(76.3[\mathrm{SE} 3.8] \mathrm{pmol} / \mathrm{L} \mathrm{v}$. 61.6 [SE 2.8]) pmol/L, $p<0.002$ ), and the glucose/insulin ratio was significantly lower $(0.092[\mathrm{SE} 0.009] \mathrm{mmol} / \mathrm{pmol} \mathrm{v}$. 0.129 [SE 0.006 ] mmol $/ \mathrm{pmol}, p=0.001)$, indicating reduced insulin sensitivity (Table 4). 
Table 2: Characteristics of participants with and without gestational diabetes mellitus*

\begin{tabular}{|c|c|c|c|}
\hline \multirow[b]{2}{*}{ Characteristic } & \multicolumn{2}{|c|}{ Mean \pm SD $†$} & \multirow[b]{2}{*}{$p$ value } \\
\hline & $\begin{array}{c}\text { Gestational } \\
\text { diabetes } \neq \\
n=365\end{array}$ & $\begin{array}{l}\text { No gestational } \\
\text { diabetes } \\
n=641\end{array}$ & \\
\hline Age, yr & $31.2 \pm 4.0$ & $29.7 \pm 3.8$ & $<0.001$ \\
\hline Length of time in Canada, yr & $8.8 \pm 7.5$ & $8.2 \pm 7.9$ & 0.2 \\
\hline $\begin{array}{l}\text { Duration of pregnancy at study enrolment, } \\
\text { wk }\end{array}$ & $26.8 \pm 2.1$ & $26.6 \pm 1.6$ & 0.1 \\
\hline \multicolumn{4}{|l|}{ Parity, no. (\%) } \\
\hline Primiparous & $123(33.7)$ & $283(44.1)$ & $<0.001$ \\
\hline Multiparous & $236(64.6)$ & $343(53.5)$ & \\
\hline Unknown & $6(1.6)$ & $15(2.3)$ & \\
\hline Smoked during pregnancy, no. (\%) & $0(0.0)$ & $2(0.3)$ & 0.5 \\
\hline Vegetarian, no. (\%) & $125(34.5)$ & $243(38.1)$ & 0.2 \\
\hline Diet quality score & $2.2 \pm 1.4$ & $2.5 \pm 1.3$ & 0.002 \\
\hline Low diet quality, no. (\%) & $121(33.4)$ & $145(22.9)$ & $<0.001$ \\
\hline Time spent engaged in active sport per wk, $\mathrm{h}$ & $1.4 \pm 2.2$ & $1.6 \pm 2.5$ & 0.4 \\
\hline \multicolumn{4}{|l|}{ Physical activity in pregnancy, no. (\%) } \\
\hline Sedentary & $97(26.6)$ & $139(21.7)$ & 0.2 \\
\hline Mild exercise & $202(55.3)$ & $373(58.2)$ & \\
\hline Moderate exercise & $64(17.5)$ & $128(20.0)$ & \\
\hline Unknown & $2(0.5)$ & $1(0.2)$ & \\
\hline Family history of diabetes, no. (\%) & $191(52.5)$ & $228(35.7)$ & $<0.001$ \\
\hline \multicolumn{4}{|l|}{ Social disadvantage index, no. (\%) } \\
\hline High & $47(12.9)$ & $90(14.0)$ & 0.9 \\
\hline Moderate & $118(32.3)$ & $213(33.2)$ & \\
\hline Low & $145(39.7)$ & $25139.2)$ & \\
\hline Unknown & $55(15.1)$ & $87(13.6)$ & \\
\hline Currently employed, no. (\%) & $196(54.0)$ & $349(54.5)$ & 0.9 \\
\hline Annual household income $\geq \$ 50000$, no. (\%) & $143(46.0)$ & $242(43.6)$ & 0.5 \\
\hline High school education, no. (\%) & $361(99.4)$ & $638(99.5)$ & 0.9 \\
\hline Prepregnancy weight, $\mathrm{kg}$ & $64.9 \pm 12.2$ & $61.3 \pm 11.8$ & $<0.001$ \\
\hline Height, $\mathrm{cm}$ & $161.6 \pm 6.2$ & $162.5 \pm 6.3$ & 0.02 \\
\hline Prepregnancy body mass index & $24.9 \pm 4.6$ & $23.2 \pm 4.3$ & $<0.001$ \\
\hline $\begin{array}{l}\text { Sum of skinfold measurements at enrolment, } \\
\mathrm{mm}\end{array}$ & $52.3 \pm 12.3$ & $47.9 \pm 12.4$ & $<0.001$ \\
\hline Triceps skinfold thickness at enrolment, mm & $28.5 \pm 6.7$ & $26.5 \pm 6.8$ & $<0.001$ \\
\hline $\begin{array}{l}\text { Subscapular skinfold thickness at enrolment, } \\
\mathrm{mm}\end{array}$ & $24.1 \pm 6.6$ & $21.5 \pm 6.5$ & $<0.001$ \\
\hline Glucose area under the curve, $\mathrm{mmol} / \mathrm{min}$ & $966.8 \pm 164.0$ & $722.4 \pm 102.5$ & $<0.001$ \\
\hline Weight gain during pregnancy, kg & $13.5 \pm 7.5$ & $14.7 \pm 7.9$ & 0.02 \\
\hline $\begin{array}{l}\text { Weight gain during pregnancy/prepregnancy } \\
\text { weight }\end{array}$ & $0.22 \pm 0.13$ & $0.25 \pm 0.15$ & $<0.001$ \\
\hline Cesarean delivery, no. (\%) & $127(35.2)$ & $177(27.9)$ & 0.02 \\
\hline $\begin{array}{l}\text { Note: } \mathrm{SD}=\text { standard deviation. } \\
\text { *Data missing for some variables. } \\
\dagger \text { Except where noted otherwise. } \\
\ddagger \text { Classified with the cut-off values derived from the Born } \\
\text { excluded. }\end{array}$ & dfford cohort. ${ }^{26} \mathrm{P}$ & ts with a history $\mathrm{c}$ & s were \\
\hline
\end{tabular}




\section{OPEN}

\section{Interpretation}

South Asian women living in Ontario had a high burden of gestational diabetes compared to the general population, with the disease affecting upward of one-third of our participants. The major determinants of gestational diabetes accounted for $65.3 \%$ of the population attributable risk and included nonmodifiable factors (age, family history of type 2 diabetes and height) as well as modifiable factors (prepregnancy weight and low diet quality). Furthermore, newborns of dysglycemic mothers had increased birth weight and body fat, and reduced insulin sensitivity, which may be implicated in their future risk of excess adiposity and type 2 diabetes.

The population attributable risk for gestational diabetes due to modifiable risk factors was $37.3 \%$. This suggests that, if South Asian women could achieve an optimal prepregnancy

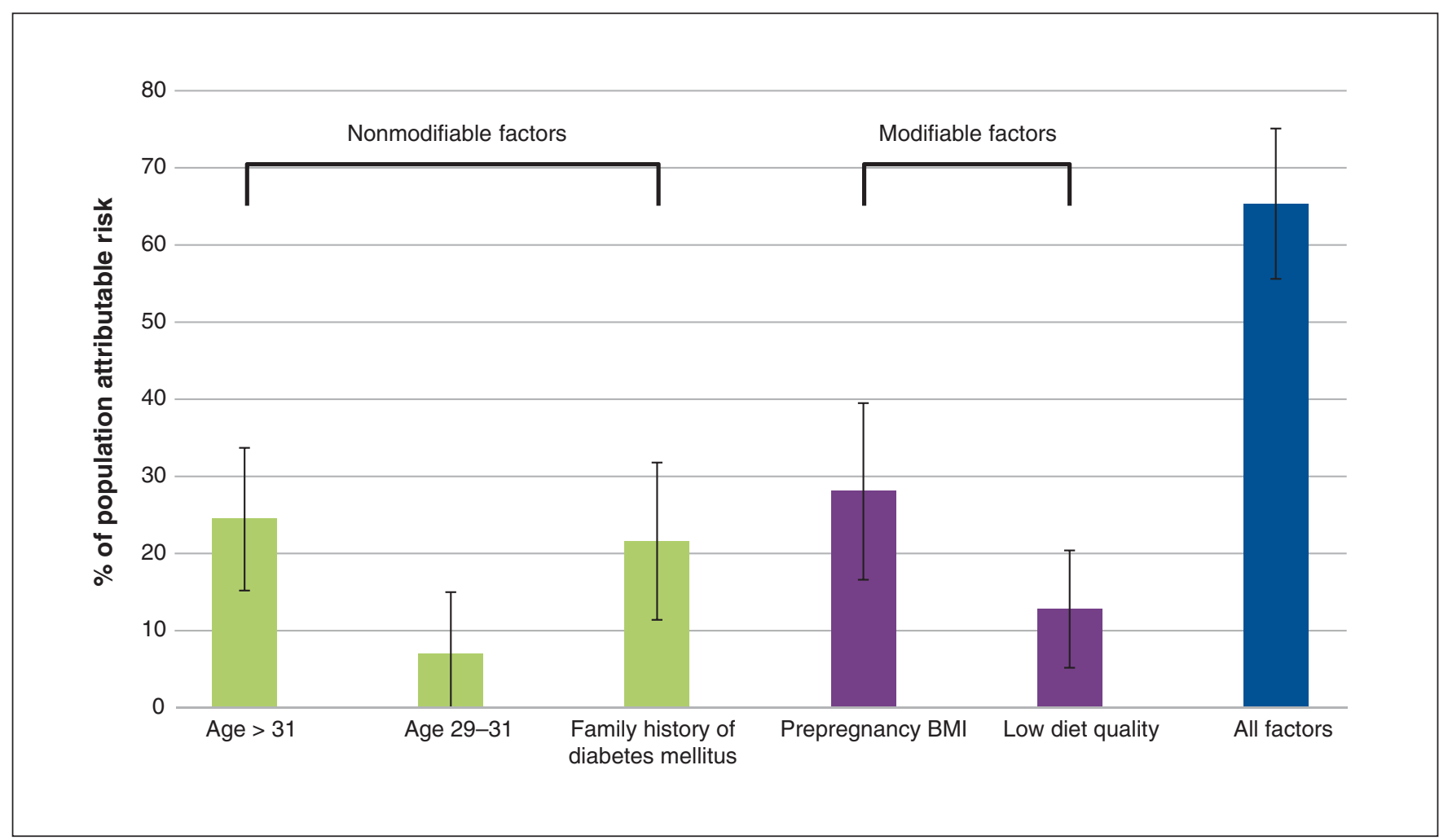

Figure 1: Partial proportional attributable risk for individual risk factors for the development of gestational diabetes mellitus among South Asian women. Error bars represent $95 \%$ confidence intervals. Note: $\mathrm{BMI}=$ body mass index.

\begin{tabular}{|c|c|c|c|}
\hline Risk factor & $\begin{array}{l}\text { OR }(95 \% \mathrm{Cl}) \text { from } \\
\text { multivariable model }\end{array}$ & $\begin{array}{c}\text { Prevalence, } \\
\%\end{array}$ & $\begin{array}{l}\text { Population attributable } \\
\text { risk } \%(95 \% \mathrm{Cl})^{*}\end{array}$ \\
\hline Age $32-43$ yr v. $<29$ yr & 2.10 (1.51 to 2.91$)$ & 36.4 & 24.5 (15.2 to 33.7$)$ \\
\hline Age 29-31 yr v. $<29$ yr & $1.34(0.94$ to 1.90$)$ & 28.6 & $7.0(-1.1$ to 15.0$)$ \\
\hline Family history of diabetes mellitus & $1.70(1.29$ to 2.23$)$ & 42.1 & 21.6 (11.4 to 31.8$)$ \\
\hline Low diet quality & $1.62(1.20$ to 2.19$)$ & 26.7 & 12.8 (5.2 to 20.4$)$ \\
\hline Body mass index $>23$ v. $\leq 23$ & $1.80(1.37$ to 2.37$)$ & 51.5 & 28.1 (16.6 to 39.5$)$ \\
\hline $\begin{array}{l}\text { Low diet quality and/or body } \\
\text { mass index }>23\end{array}$ & & 63.5 & 37.3 (25.9 to 48.7$)$ \\
\hline All factors & & & $65.3(55.6$ to 75.1$)$ \\
\hline \multicolumn{4}{|c|}{$\begin{array}{l}\text { Note: } \mathrm{Cl}=\text { confidence interval, } \mathrm{OR}=\text { odds ratio. } \\
{ }^{*} \mathrm{Continuous} \text { factors needed to be categorized: age was divided into tertiles, and body mass index was split into } 3 \text { categories } \\
(<18.5,18.5-23 \text { and }>23) \text {; the highest category was selected as it was significantly different from the lower categories. }\end{array}$} \\
\hline
\end{tabular}




\begin{tabular}{|c|c|c|c|}
\hline \multirow[b]{2}{*}{ Characteristic } & \multicolumn{2}{|c|}{ Mean $\pm \mathrm{SE}^{\star} \dagger$} & \multirow[b]{2}{*}{$p$ value } \\
\hline & $\begin{array}{c}\text { Gestational } \\
\text { diabetes* }^{*} \\
n=359\end{array}$ & $\begin{array}{c}\text { No gestational } \\
\text { diabetes } \\
n=630\end{array}$ & \\
\hline Male, no. (\%) & $188(52.4)$ & $304(48.2)$ & \\
\hline Gestational age, wk & $38.8 \pm 1.6$ & $39.3 \pm 1.4$ & \\
\hline \multicolumn{4}{|l|}{ Size for gestational age, $\ddagger$ no. (\%) } \\
\hline Large & $48(13.4)$ & $55(8.7)$ & 0.02 \\
\hline Average & $277(77.2)$ & $493(78.2)$ & \\
\hline Small & $24(6.7)$ & $64(10.2)$ & \\
\hline Unknown & $10(2.8)$ & $18(2.8)$ & \\
\hline Birth weight, g & $3267 \pm 23$ & $3181 \pm 17$ & 0.005 \\
\hline Length, $\mathrm{cm}$ & $51.0 \pm 0.1$ & $51.1 \pm 0.1$ & 0.7 \\
\hline Waist circumference, $\mathrm{cm}$ & $30.8 \pm 0.1$ & $30.3 \pm 0.1$ & 0.009 \\
\hline Head circumference, $\mathrm{cm}$ & $34.1 \pm 0.1$ & $34.0 \pm 0.1$ & 0.4 \\
\hline Sum of skinfold measurements, mm & $11.7 \pm 0.1$ & $11.2 \pm 0.1$ & 0.007 \\
\hline Triceps skinfold thickness, mm & $6.1 \pm 0.1$ & $5.9 \pm 0.1$ & 0.05 \\
\hline Subscapular skinfold thickness, mm & $5.5 \pm 0.1$ & $5.2 \pm 0.1$ & 0.002 \\
\hline Ponderal index§ & $24.8 \pm 0.2$ & $24.0 \pm 0.1$ & 0.002 \\
\hline Placental weight, g & $503.2 \pm 8.1$ & $474.9 \pm 5.8$ & 0.007 \\
\hline Cord blood glucose level, $\mathrm{mmol} / \mathrm{L}$ & $4.1 \pm 0.1$ & $4.1 \pm 0.0$ & 0.9 \\
\hline Cord blood insulin (log) level, pmol/L & $76.3 \pm 3.8$ & $61.6 \pm 2.8$ & 0.002 \\
\hline Glucose/insulin ratio, $\mathrm{mmol} / \mathrm{pmol}$ & $0.092 \pm 0.009$ & $0.129 \pm 0.006$ & 0.001 \\
\hline \multicolumn{4}{|c|}{$\begin{array}{l}\text { Note: } \mathrm{SE}=\text { standard error. } \\
\text { *Except where noted otherwise. } \\
\text { †Adjusted for gestational age, sex and insulin use by mother during pregnancy. } \\
\text { †Determined from gestational age and sex-specific percentiles from study data. } \\
\text { §Birth weight }\left(\mathrm{kg} / \text { /birth length }\left(\mathrm{m}^{3}\right) \text {. }\right. \\
\text { qNon log insulin level used. }\end{array}$} \\
\hline
\end{tabular}

weight (i.e., BMI < 23) and improve their diet quality, about one-third of cases of gestational diabetes in this population could be prevented. A BMI of $23-25$ is often classified as normal prepregnancy weight in white women but likely represents overweight and excess adiposity in South Asian women. ${ }^{37,38}$ In our study, women with gestational diabetes had a higher prepregnancy weight (by $3 \mathrm{~kg}$ ), were shorter (by $1 \mathrm{~cm}$ ) and had significantly greater body fat than those without gestational diabetes. Prepregnancy BMI was the dominant predictor of gestational diabetes, more so than weight gain during pregnancy, which, as expected, was lower in participants with gestational diabetes than in those without gestational diabetes. This highlights the importance of public health messaging to South Asian women who are contemplating pregnancy to aim for an optimal weight before pregnancy as a prevention strategy against gestational diabetes. ${ }^{39}$ To our knowledge, such messaging is not routinely provided by primary care physicians or public health specialists and requires an integrated approach involving primary health care and policy initiatives..$^{40}$

The low-quality diet in the South Asian Birth Cohort (START) study was characterized by higher consumption of meat, rice and fried foods, and was lower in raw or cooked vegetables, whereas a high-quality diet included higher consumption of vegetables, legumes and whole-grain breads. ${ }^{25}$ Given that the population attributable risk for gestational diabetes due to low diet quality in our study was $12.8 \%$, a modified diet in which fried foods and meat were replaced with more vegetable protein and raw and cooked vegetables, and refined grains were replaced with whole grains might reduce gestational diabetes in this population by up to $13 \%$. A Cochrane review suggested that dietary interventions are more effective than exercise alone or mixed interventions in preventing gestational diabetes. ${ }^{41}$ We identified no randomized trials that aimed to reduce prepregnancy BMI or alter diet quality in pregnancy as a method to prevent gestational diabetes in South Asian women living in high-income countries.

Our observation that a family history of type 2 diabetes is a strong risk factor for gestational diabetes is consistent with prior studies. ${ }^{15,42-44}$ Other investigators have hypothesized that women in whom gestational diabetes develops may carry a greater genetic load of variants associated with $\beta$-cell dysfunction and insulin resistance, which, in turn, increases their 
babies' genetic load for these conditions. ${ }^{45,46} \mathrm{We}$ also observed that maternal hyperglycemia was associated with increased newborn birth weight, more adipose tissue in newborns, a higher proportion of infants who were large for gestational age and a larger placenta. Furthermore, babies of women with gestational diabetes had reduced insulin sensitivity. Chronic exposure of the growing fetus to hyperglycemia may induce changes in the regulation of gene expression, resulting in reduced insulin secretion or action. ${ }^{47}$

\section{Strengths and limitations}

Strengths of our study include that it was a large prospective birth cohort study with direct measurement of glycemic status by means of the oral glucose tolerance test. In addition, we directly measured the adiposity of participants and their babies. The study was limited by the fact that our cohort was not a random sample of the population, which may have overestimated the burden of dysglycemia; however, we recruited participants from primary care settings and specialist obstetrical clinics. Furthermore, our dietary questionnaire was selfreported. The lack of random sampling does not affect our association analyses, which remain internally valid, and the food frequency questionnaire is the gold standard of dietary assessment tools.

\section{Conclusion}

Gestational diabetes affects up to one-third of South Asian women living in Canada. Modifiable risk factors for this disease include prepregnancy weight and low diet quality. Newborns exposed to the highest maternal glucose levels had increased birth weight, increased body fat and lower insulin sensitivity. Intervention studies to lower prepregnancy weight and to prevent gestational diabetes in this high-risk population are needed.

\section{References}

1. HAPO Study Cooperative Research Group; Metzger BE, Lowe LP, Dyer $\mathrm{AR}$, et al. Hyperglycemia and adverse pregnancy outcomes. $N$ Engl $7 \mathrm{Med}$ 2008;358:1991-2002.

2. Vohr BR, Boney CM. Gestational diabetes: The forerunner for the development of maternal and childhood obesity and metabolic syndrome? 7 Matern Fetal Neonatal Med 2008;21:149-57.

3. Aceti A, Santhakumaran S, Logan KM, et al. The diabetic pregnancy and offspring blood pressure in childhood: a systematic review and meta-analysis. Diabetologia 2012;55:3114-27.

4. Kim SY, England JL, Sharma JA, et al. Gestational diabetes mellitus and risk of childhood overweight and obesity in offspring: a systematic review. Exp Diabetes Res 2011;2011:541308.

5. Sattar N, Gill JMR. Type 2 diabetes in migrant south Asians: mechanisms, mitigation, and management. Lancet Diabetes Endocrinol 2015;3:1004-16.

6. Abate N, Chandalia M. Ethnicity and type 2 diabetes: focus on Asian Indians. 7 Diabetes Complications 2001;15:320-7.

7. McKeigue PM, Shah B, Marmot MG. Relation of central obesity and insulin resistance with high diabetes prevalence and cardiovascular risk in South Asians. Lancet 1991;337:382-6.

8. Anand SS, Yusuf S, Vuksan V, et al. Differences in risk factors, atherosclerosis, and cardiovascular disease between ethnic groups in Canada: the Study of Health Assessment and Risk in Ethnic groups (SHARE). Lancet 2000;356:279-84.

9. Rana A, de Souza RJ, Kandasamy S, et al. Cardiovascular risk among South Asians living in Canada: a systematic review and meta-analysis. CMAZ Open 2014;2:E183-91.

10. Mohanty SA, Woolhandler S, Himmelstein DU, et al. Diabetes and cardiovascular disease among Asian Indians in the United States. 7 Gen Intern Med 2005;20:474-8.

11. Mukerji G, Chiu M, Shah BR. Gestational diabetes mellitus and pregnancy outcomes among Chinese and South Asian women in Canada. 7 Matern Fetal Neonatal Med 2013;26:279-84.
12. Jenum AK, Mørkrid K, Sletner L, et al. Impact of ethnicity on gestational diabetes identified with the WHO and the modified International Association of Diabetes and Pregnancy Study Groups criteria: a population-based cohort study. Eur 7 Endocrinol 2012;166:317-24.

13. Urquia M, Glazier RH, Berger H, et al. Gestational diabetes among immigrant women. Epidemiology 2011;22:879-80.

14. Savitz DA, Janevic TM, Engel SM, et al. Ethnicity and gestational diabetes in New York City, 1995-2003. B7OG 2008;115:969-78.

15. Solomon CG, Willett WC, Carey VJ, et al. A prospective study of pregravid determinants of gestational diabetes mellitus. FAMA 1997;278:1078-83.

16. Berkowitz GS, Lapinski RH, Wein R, et al. Race/ethnicity and other risk factors for gestational diabetes. Am 7 Epidemiol 1992;135:965-73.

17. Hedderson MM, Darbinian JA, Quesenberry CP, et al. Pregravid cardiometabolic risk profile and risk for gestational diabetes mellitus. Am 7 Obstet Gynecol 2011;205:55.e1-7.

18. Zargar AH, Sheikh MI, Bashir MI, et al. Prevalence of gestational diabetes mellitus in Kashmiri women from the Indian subcontinent. Diabetes Res Clin Pract 2004:66:139-45.

19. Arora GP, Thaman RG, Prasad RB, et al. Prevalence and risk factors of gestational diabetes in Punjab, North India: results from a population screening program. Eur 7 Endocrinol 2015;173:257-67.

20. Krishnaveni GV, Hill JC, Veena SR, et al. Low plasma vitamin $B_{12}$ in pregnancy is associated with gestational 'diabesity' and later diabetes. Diabetologia 2009;52:2350-8.

21. American Diabetes Association. 1. Strategies for improving care. Diabetes Care 2016;39(Suppl 1):S6-12.

22. Canadian Diabetes Association Clinical Practice Guidelines Expert Committee; Thompson D, Berger H, Feig D, et al. Diabetes and pregnancy. Can 7 Diabetes 2013;37(Suppl 1):S168-83

23. Babu GR, Garadi L, Murthy GVS, et al. Effect of hyperglycaemia in pregnancy on adiposity in their infants in India: a protocol of a multicentre cohort study. BM7 Open 2014;4:e005417.

24. West J, Lawlor DA, Fairley L, et al. Differences in socioeconomic position, lifestyle and health-related pregnancy characteristics between Pakistani and White British women in the Born in Bradford prospective cohort study: the influence of the woman's, her partner's and their parents' place of birth. BMF Open 2014:4:e004805.

25. Anand SS, Vasudevan A, Gupta M, et al.; START Cohort Study Investigators. Rationale and design of South Asian Birth Cohort (START): a Canada-India collaborative study. BMC Public Health 2013;13:79.

26. Farrar D, Fairley L, Santorelli G, et al. Association between hyperglycaemia and adverse perinatal outcomes in south Asian and white British women: analysis of data from the Born in Bradford cohort. Lancet Diabetes Endocrinol 2015;3:795-804.

27. Merchant AT, Anand SS, Vuksan V, et al.; SHARE and SHARE-AP Investigators. Protein intake is inversely associated with abdominal obesity in a multiethnic population. 7 Nutr 2005;135:1196-201.

28. Kelemen LE, Anand SS, Vuksan V, et al.; SHARE Investigators. Development and evaluation of cultural food frequency questionnaires for South Asians, Chinese, and Europeans in North America. 7 Am Diet Assoc 2003;103:1178-84.

29. Iqbal R, Anand S, Ounpuu S, et al.; INTERHEART Study Investigators. Dietary patterns and the risk of acute myocardial infarction in 52 countries: results of the INTERHEART study. Circulation 2008;118:1929-37.

30. Anand SS, Razak F, Davis AD, et al. Social disadvantage and cardiovascular disease: development of an index and analysis of age, sex, and ethnicity effects. Int 7 Epidemiol 2006;35:1239-45.

31. Sommer C, Mørkrid K, Jenum AK, et al. Weight gain, total fat gain and regional fat gain during pregnancy and the association with gestational diabetes: a population-based cohort study. Int 7 Obes (Lond) 2014;38:76-81.

32. Leary SD, Godfrey KM, Greenaway LJ, et al. Contribution of the umbilical cord and membranes to untrimmed placental weight. Placenta 2003;24:276-8.

33. Yajnik CS, Fall CHD, Coyaji KJ, et al. Neonatal anthropometry: the thin-fat Indian baby. The Pune Maternal Nutrition Study. Int 7 Obes Relat Metab Disord 2003;27:173-80.

34. Winer B. Statistical principles in experimental design. 2nd ed. London (UK): McGraw-Hill Kogakusha, Ltd.; 1971.

35. 2011 census of Canada: topic-based tabulations. Age (131) and sex (3) for the population of Canada, provinces, territories, census divisions, census subdivisions and dissemination areas, 2011 Census. Cat no 98-311-XCB2011018. Ottawa: Statistics Canada; 2012.

36. Engel LS, Chow WH, Vaughan TL, et al. Population attributable risks of esophageal and gastric cancers. 7 Natl Cancer Inst 2003;95:1404-13.

37. Razak F, Anand SS, Shannon H, et al. Defining obesity cut points in a multiethnic population. Circulation 2007;115:2111-8.

38. Gray LJ, Yates T, Davies MJ, et al. Defining obesity cut-off points for migrant South Asians. PLoS One 2011;6:e26464.

39. Poston L, Caleyachetty R, Cnattingius S, et al. Preconceptional and maternal obesity: epidemiology and health consequences. Lancet Diabetes Endocrinol 2016; 4:1025-36.

40. Hanson M, Barker M, Dodd JM, et al. Interventions to prevent maternal obesity before conception, during pregnancy, and post partum. Lancet Diabetes Endocrinol 2017;5:65-76. 
41. Bain E, Crane M, Tieu J, et al. Diet and exercise interventions for preventing gestational diabetes mellitus. Cochrane Database Syst Rev 2015;(4):CD010443.

42. Ben-Haroush A, Yogev Y, Hod M. Epidemiology of gestational diabetes mellitus and its association with type 2 diabetes. Diabet Med 2004;21:103-13.

43. King H. Epidemiology of glucose intolerance and gestational diabetes in women of childbearing age. Diabetes Care 1998;21(Suppl 2):B9-13.

44. Williams MA, Qiu C, Dempsey JC, et al. Familial aggregation of type 2 diabetes and chronic hypertension in women with gestational diabetes mellitus. 7 Reprod Med 2003;48:955-62.

45. Vaag A, Brøns C, Gillberg L, et al. Genetic, nongenetic and epigenetic risk determinants in developmental programming of type 2 diabetes. Acta Obstet Gynecol Scand 2014;93:1099-108.

46. Hattersley AT, Tooke JE. The fetal insulin hypothesis: an alternative explanation of the association of low birthweight with diabetes and vascular disease. Lancet 1999;353:1789-92.

47. Gilbert ER, Liu D. Epigenetics: the missing link to understanding $\beta$-cell dysfunction in the pathogenesis of type 2 diabetes. Epigenetics 2012;7:841-52.

Affiliations: Departments of Medicine (Anand, Teo, Zulyniak, Gerstein), Health Research Methods, Evidence and Impact (Shaikh, de Souza, Beyene), Pediatrics (Wahi, Morrison) and Obstetrics and Gynecology (McDonald), McMaster University; Population Health Research Institute (Anand, Teo); Hamilton Health Sciences (Anand, Teo, Schulze, Desai, Abdalla), Hamilton, Ont.; Canadian Cardiovascular Research Network (Gupta), Brampton, Ont.; Peel Public Health (de Villa), Mississauga, Ont.

Contributors: Sonia Anand conceived the study, and Sonia Anand and Milan Gupta designed the study. Sonia Anand, Milan Gupta, Dipika Desai and Nora Abdalla obtained the data. Karleen Schulze, Mateen
Shaikh, Michael Zulyniak and Russell de Souza analyzed the data. Sonia Anand drafted the manuscript. Sonia Anand, Milan Gupta, Koon Teo, Hertzel Gerstein, Karleen Schulze, Dipika Desai, Michael Zulyniak, Russell de Souza, Gita Wahi, Mateen Shaikh, Joseph Beyene, Nora Abdalla and Eileen de Villa contributed to interpreting the data and revising the manuscript critically for important intellectual content. Katherine Morrison contributed to revising the work critically for important intellectual content. Sarah McDonald provided subject matter expertise in gestational diabetes and other obstetrical factors, and contributed to interpreting the data and revising the manuscript critically for important intellectual content. All of the authors approved the final version to be published and agreed to act as guarantors of the work.

Acknowledgements: South Asian Birth Cohort (START) study data were collected as part of a bilateral program funded by the Indian Council of Medical Research/Canadian Institutes of Health Research (grant INC-109205). This study was supported by Heart and Stroke Foundation of Canada grant NA7283. Sonia Anand is supported by a Tier 1 Canada Research Chair in Ethnic Diversity and Cardiovascular Disease, and a Heart and Stroke Foundation/Michael G. DeGroote Chair in Population Health Research at McMaster University. Sarah McDonald is supported by a Tier 2 Canada Research Chair. Hertzel Gerstein is supported by a McMaster-Aventis Population Health Institute Chair in Diabetes Research.

Supplemental information: For reviewer comments and the original submission of this manuscript, please see www.cmajopen.ca/content $/ 5 / 3 /$ E604/suppl/DC1. 